\title{
Investigation of Pneumocystis jirovecii colonization in patients with chronic pulmonary diseases in the People's Republic of China
}

This article was published in the following Dove Press journal:

International Journal of COPD

29 September 2015

Number of times this article has been viewed

\author{
Dong-Dong Wang' \\ Ming-Quan Zheng', \\ Nan Zhang ${ }^{2}$ \\ Chun-Li An ${ }^{2}$
}

'Department of Obstetrics and Gynecology, Shengjing Hospital, China Medical University, Shenyang, People's Republic of China; ${ }^{2}$ Department of Microbiology and Parasitology, College of Basic Medical Science, China Medical University, Shenyang, People's Republic of China; ${ }^{3}$ Richard King Mellon Foundation Institute for Pediatric Research, Children's Hospital of Pittsburgh of UPMC, Pittsburgh, PA, USA
Correspondence: Dong-Dong Wang Department of Obstetrics and Gynecology, Shengjing Hospital, China Medical University, No 36. SanHao Street, Heping District, Shenyang 100004, People's Republic of China

Tel +8624238966I5

Email wlittlepearI@I63.com

Chun-Li An

Department of Microbiology and Parasitology, College of Basic Medical Sciences, China Medical University, No

92. Beier Load, Heping District, Shenyang I I0I 22, People's Republic of China

Tel +862431939030

Email cmucl@।26.com
Background: The detection of Pneumocystis jirovecii DNA in respiratory specimen from individuals who do not have signs or symptoms of pneumonia has been defined as colonization. The role of $P$. jirovecii colonization in the development or progression of various lung diseases has been reported, but little information about $P$. jirovecii colonization in patients is available in the People's Republic of China.

Objective: To determine the prevalence of $P$. jirovecii colonization in patients with various pulmonary diseases, including the acute and stable stage of COPD, interstitial lung diseases, cystic fibrosis, and chronic bronchiectasis.

Materials and methods: A loop-mediated isothermal amplification (LAMP) and a conventional polymerase chain reaction (PCR) method for detecting $P$. jirovecii were developed. Ninety-eight HIV-negative patients who were followed-up and who had undergone bronchoscopy for diagnosis of various underlying respiratory diseases were included in the study. Sputa of these patients were analyzed with LAMP amplification of $P$. jirovecii gene. In addition, conventional PCR, Giemsa and Gomori's methenamine silver nitrate staining assays were applied to all specimens.

Results: The sensitivity and specificity test showed that there was no cross-reaction with other fungi or bacteria in detecting the specific gene of $P$. jirovecii by LAMP, and the minimum detection limits by LAMP was 50 copies $/ \mathrm{mL}$. P. jirovecii DNA was detected in 62 of 98 (63.3\%) sputa specimens by LAMP assay and $22.45 \%$ (22/98) by conventional PCR. However, no $P$. jirovecii cysts were found by Giemsa and Gomori's methenamine silver nitrate in all of gene-positive specimens.

Conclusion: The results of our study showed that prevalence of $P$. jirovecii colonization is particularly high in patients with chronic pulmonary diseases in the People's Republic of China, and the LAMP method is better for evaluation of the colonization of $P$. jirovecii in sputum specimen than conventional PCR.

Keywords: Pneumocystis jirovecii, colonization, chronic pulmonary diseases, loop-mediated isothermal amplification

\section{Introduction}

A high prevalence of Pneumocystis jirovecii colonization was observed in patients with chronic pulmonary diseases or various lung underlying diseases, ${ }^{1-3}$ and the important roles of $P$. jirovecii colonization in development or progression of various lung diseases is a concern. ${ }^{4-6}$ Patients who are carriers of $P$. jirovecii are at a higher risk of $P$. jirovecii pneumonia, and could also present a problem for public health since colonized patients could act as a major reservoir and source of infection for susceptible subjects. ${ }^{7,8}$ Detection of carriage or colonization of $P$. jirovecii is important 
for understanding its epidemiology and its correlation with the lung disease. Even though a number of Pneumocystis pneumonia (PCP) cases has been reported in the People's Republic of China, ${ }^{9}$ scarce data is available regarding the carriage or colonization of $P$. jirovecii in immunocompetent patients. Loop-mediated isothermal amplification (LAMP) is an innovative molecular technique to amplify a specific target gene. ${ }^{10-12}$ To evaluate the prevalence of $P$. jirovecii colonization in patients with pulmonary diseases, we have developed and evaluated a LAMP method to detect the $P$. jirovecii gene from sputum specimens of the patients with chronic pulmonary diseases. The specimens were also microbiologically examined.

\section{Materials and methods}

\section{Patients and specimens}

Ninety-eight HIV-negative patients suffering from chronic pulmonary diseases were incorporated in this study. They were consecutively treated in Department of Internal Medicine of the First Affiliated Hospital of China Medical University from June 2011 to October 2013. Every patient underwent a clinical and biochemical examination using a standardized protocol, and HIV antibody was tested using Anti-HIV-1+2 antibodies ELISA diagnostic kit. The patients had undergone bronchoscopy for diagnosis of various underlying respiratory diseases. The inclusion criteria was in hospital treatment for chronic pulmonary disease, including acute exacerbations of COPD (AECOPD), stable stage of COPD, interstitial lung diseases (ILDs), cystic fibrosis $(\mathrm{CF})$, and chronic bronchiectasis $(\mathrm{CB})$ patients. The diseases were diagnosed according to the People's Republic of China Ministry of Health in 2011 to develop the disease diagnostic criteria.

\section{Specimen processing}

Blood and sputum specimens were collected from 98 patients before they received the corticoid or antibiotics treatment. Informed consent was obtained from all patients.

Sputum specimens were obtained from patient by spontaneous production. In order to avoid contamination of oral microbe, patients first gargled saline three times, prior to coughing up the sputum from deep respiratory tract when collecting specimens. Sputum specimens were promptly sent to the central laboratory of the hospital for bacterial culture and quantization. Co-infecting bacteria was analyzed using the automated bacterial identification system (ATB system, BioMérieux, Marcy-l'Étoile, France) following the bacterial or fungi culture. $P$. jirovecii organisms were identified microscopically by a modified Giemsa staining (Diff-Quik) method and a modified Gomori's methenamine silver nitrate staining method as previously described. ${ }^{13,14}$

The blood samples were used for $\mathrm{CD}^{+}{ }^{+} \mathrm{T}$-cell measurement. ${ }^{12}$ Sera were analyzed on BD FACSCalibur and the test kit. The normal critical value of $\mathrm{CD}^{+} \mathrm{T}$-cell in blood was set to 410 cells $/ \mathrm{mm}^{3}$ according to the reference of test kit. Patients will be considered as immunocompetent when CD4 cell $>410$ cells $/ \mathrm{mm}^{3}$, and they will be identified as immunocompromised when the $\mathrm{CD}^{+} \mathrm{T}$-cell counts $<410$ cells $/ \mathrm{mm}^{3}$.

\section{DNA preparation}

DNA was extracted from the sputum specimens. ${ }^{15}$ The sputa were treated with sodium hydroxide and centrifuged at 12,000 rpm for 5 minutes. The supernatant was discarded, and the precipitate was washed three times with TE buffer. Precipitated specimens were mixed with distilled water, incubated at $100^{\circ} \mathrm{C}$ for 15 minutes and centrifuged at $12,000 \mathrm{rpm}$ for 10 minutes. The supernatants were stored at $-20^{\circ} \mathrm{C}$ until DNA extraction. Following proteinase $\mathrm{K}$ digestion, DNA was extracted with a Genomic DNA Kit (Tiangen Technology, Beijing, People's Republic of China) in accordance with the manufacturer's instructions and stored at $-80^{\circ} \mathrm{C}$.

\section{Design of primers}

The gene sequences of Pneumocystis core ribosomal bodies small subunit 16s rRNA was obtained from GenBank, and compared with the 16s rRNA of Pneumocystis carinii (AB266392), Pneumocystis murina (AY532651), Blastocystis, and Candida species. The specific LAMP primer was created by web tool Primer Explorer V4 (http:// primerexplorer.jp/elamp4.0.0/index.html). Primers and their sequences used in LAMP are showed in Table 1. LAMP primers F3 and B3 were also used as conventional polymerase chain reaction (PCR) primers.

Table I Primers and their sequences used in LAMP

\begin{tabular}{ll}
\hline Primers & Sequences $\left(\mathbf{5}^{\prime} \mathbf{- 3} \mathbf{3}^{\prime}\right)$ \\
\hline F3 & ATCAGATACCGTCGTAGTCTTA \\
B3 & GCTCTCAATCTGTCAATCCTTA \\
FIP & TTCAGCCTTGCGACCATACTCCTCGCTCGGCATCTTATG \\
BIP & AAGGGCACCACCAGGAGTTATGTCTGGACCTGGTGAG \\
Loop F & GGAACCCGAAGACTTTGATTTC \\
Loop B & TGCGGCTTAATTTGACTCAAC \\
\hline
\end{tabular}

Abbreviation: LAMP, loop-mediated isothermal amplification. 


\section{LAMP assay}

The LAMP reaction was performed ${ }^{11}$ in a final volume of $25 \mu \mathrm{L}$ which contained $1 \times$ LAMP reaction buffer (the buffer contained $10 \mathrm{mM}$ Tris- $\mathrm{HCl}(\mathrm{pH} 8.8), 5 \mathrm{mM} \mathrm{KCl}, 5 \mathrm{mM}$ $\left(\mathrm{NH}_{4}\right)_{2} \mathrm{SO}_{4}, 4 \mathrm{mM} \mathrm{MgSO}_{4}, 0.1 \%$ Tween 20 , and $0.4 \mathrm{M}$ betaine (Sigma-Aldrich Co., St Louis, MO, USA)), 8 units of the Bst DNA polymerase (New England Biolabs, Ipswich, MA, USA), 100 ng of test DNA, and primers of 40 pmol (FIP and BIP), 20 pmol (Loop B and Loop F), and 5 pmol (F3 and B3). The mixture was incubated at $63^{\circ} \mathrm{C}$ in a water bath for 60 minutes. Detection of LAMP products was through visual fluorescence by adding $4 \times$ SYBR Green I (Thermo Fisher Scientific, Waltham, MA, USA) to $25 \mathrm{~mL}$ of LAMP product. The LAMP product was also electrophoresed on $1.5 \%$ agarose gel and visualized by UV gel imaging analyzer (Gel Imaging System, Shinova Co. Ltd., Shanghai, People's Republic of China); or by observing the fluorescence collection volume by a real-time PCR instrument (ABI 7500; Thermo Fisher Scientific) for 60 minutes.

\section{PCR and plasmid preparation}

PCR was performed with the F3 and B3 primers as forward and reverse primers to confirm their specificity. A previously described PCR technique ${ }^{14,15}$ was used to amplify the Pneumocystis mitochondrial 16s rRNA gene. PCR conditions were as follows: the reaction was denatured at $95^{\circ} \mathrm{C}$ for 2.5 minutes, followed by 35 cycles of amplification at $94^{\circ} \mathrm{C}$ for 1 minute, $65^{\circ} \mathrm{C}$ for 1 minute, and $72^{\circ} \mathrm{C}$ for 1 minute, then with a final extension step at $72^{\circ} \mathrm{C}$ for 5 minutes. Finally, the PCR products were analyzed by electrophoresis and stained with ethidium bromide. The PCR product was ligated into the TA cloning vector pMD18-T (Takara BIO Co., Ltd., Dalian, People's Republic of China). To prevent false-positives from contamination, pipettes with filters were used in all procedures. DNA extraction, preparation of the reaction mixture, PCR amplification, and detection were performed in separate areas under a laminar flow hood. To detect any cross-contamination, samples included a blank control or distilled water.

\section{Sensitivity and specificity of the LAMP assay}

The sensitivity of the LAMP method was examined using serial dilutions of Pneumocystis DNA copies in a plasmid solution. Detection limit of LAMP were measured and compared with that of the PCR. The specificity of the LAMP detecting was validated through the parallel and comparing test with Candida albicans, Candida tropicalis, Candida parapsilosis, and Candida glabrata, Mycoplasma pneumoniae
(FH strain), Hemolytic streptococcus, methicillin-resistant Staphylococcus aureus strains in the same condition. Equal amounts of genomic DNA for each bacterium at $100 \mathrm{ng}$ were used as the template. The specificity was also compared through detecting the sputum specimens of patient, the lungs of PCP positive model rat, or negative rat (ten rats, respectively). The amplified products of LAMP were examined separately using real-time turbidity, visualized by either the naked eye or using ultraviolet light after adding SYBR Green I, and tested by gel electrophoresis. The LAMP positive product was confirmed by sequencing with 16S rRNA of $P$. jirovecii.

\section{Statistical analysis}

Pearson chi-square test and continuous correction chi-square test were used for assessing differences between samples. Fisher's exact test was used when the samples number $<40$ or the expected value $<1$. Results were considered significant at $P<0.05$. Statistical analyses were performed using the Statistical Package for Serial Studies for personal computers (SPSS version 12; SPSS Inc., Chicago, IL, USA).

\section{Ethics}

This study was conducted in accordance with the amended Declaration of Helsinki, and approved by the Institutional Review Board of Shengjing Hospital and the First Affiliated Hospital, China Medical University (AF-SOP-07-1). Informed consent was obtained from all patients.

\section{Results}

Ninety-eight patients were included in this study. The mean age of patients was $62 \pm 9.45$ years (from 22 to 91 years old). Fifty-six (57.1\%) were male. Distribution according to pulmonary diseases was $48.0 \%$ (47/98) COPD, including 15 acute stage and 32 stable stage of COPD; $25.5 \%$ (25/98) ILDs, including five idiopathic pulmonary fibrosis, five fibrosing lung disease associated with connective tissue disease, three sarcoidosis, eight cryptogenic organizing pneumonia, and four diffuse alveolar hemorrhage; $18.4 \%$ (18/98) CF and $8.2 \%(8 / 98)$ CB (Table 2).

\section{The LAMP assay}

The results of sensitivity tested for LAMP method compared with PCR was shown in Figure 1. The minimum detection limits for LAMP was 50 copies $/ \mathrm{mL}$, whereas the conventional PCR could amplify $10^{4}$ copies $/ \mathrm{mL}$. The specificity of the LAMP method showed that there was no crossreaction with $C$. albicans, $C$. tropicalis, $C$. parapsilosis, and 
Table 2 Pneumocystis jirovecii colonization in patients with chronic lung diseases

\begin{tabular}{llll}
\hline Disease & Positive & Total & Positive rate (\%) \\
\hline COPD & 25 & 47 & $53.2^{*}$ \\
Acute stage (AECOPD) & 10 & 15 & $66.7^{\nabla}$ \\
$\quad$ Stable stage & 15 & 32 & 46.9 \\
ILDs & 18 & 25 & 72.0 \\
$\quad$ Idiopathic pulmonary fibrosis & 3 & 5 & 60.0 \\
$\quad$ Fibrosing lung disease associated with connective tissue disease & 4 & 5 & 80.0 \\
Sarcoidosis & 2 & 3 & 66.7 \\
Cryptogenic organizing pneumonia & 6 & 8 & 75.0 \\
$\quad$ Diffuse alveolar hemorrhage & 3 & 45.0 \\
CF & 14 & 18 & 77.8 \\
CB & 5 & 8 & 62.5 \\
Total & 62 & 98 & \\
\hline
\end{tabular}

Note: *Compared with ILDs, CF, and CB, $P>0.05 ;{ }^{\nabla}$ Compared with stable stage, $P>0.05$.

Abbreviations: AECOPD, acute exacerbations of COPD; ILDs, interstitial lung diseases; CF, cystic fibrosis; CB, chronic bronchiectasis.

C. glabrata, M. pneumoniae (FH strain), H. streptococcus, methicillin-resistant $S$. aureus strains. The results of LAMP detecting the Pneumocystis gene in the sputum specimens of patient and the lungs of PCP model rats were positive, but it was negative in control rats. The positive results were consistent with the three examined methods, and difference of the positive and negative are apparent in Figure 2.

The gene were detected in $62(63.3 \%)$ of the 98 patients by the LAMP method and 22/98 $(22.5 \%)$ by conventional PCR $(P<0.05)$. The positive rate of $P$. jirovecii was $53.2 \%$ in COPD patients, and it was $72.0 \%, 77.8 \%$, and $62.5 \%$ in ILDs, CF, and CB patients, respectively (Table 2 ). No $P$. jirovecii organism was found in any of the 98 sputum specimens by Giemsa and Gomori's methenamine silver nitrate stain. The results of co-infecting identification showed that co-infecting bacteria or fungus was detected in 62 cases, and the positive rate of
$P$. jirovecii was $63.3 \%$ in co-infecting patients, and $75.0 \%$ in non-co-infecting patients, but was not statistically different $(P>0.05)$. The species of microorganism in co-infecting patients were listed in Table 3 , showing no statistical difference $(P>0.05)$. The species of co-infecting microorganism in patients with various pulmonary disease subgroups were listed in Table 4, no significant difference was found.

The circulating $\mathrm{CD}^{+}$lymphocyte counts were tested by the flow cytometry. The detected results are shown in Table 5. The $P$. jirovecii positive rate in $<410$ cells $/ \mathrm{mm}^{3}$ subjects was more than in $\mathrm{CD}_{4}$ counts $>410$ cells $/ \mathrm{mm}^{3}$ subjects $(80.0 \%$ vs $57.5 \%, P<0.05)$.

\section{Discussion}

As an innovative molecular technique, LAMP requires only a heating device and isothermal conditions to amplify
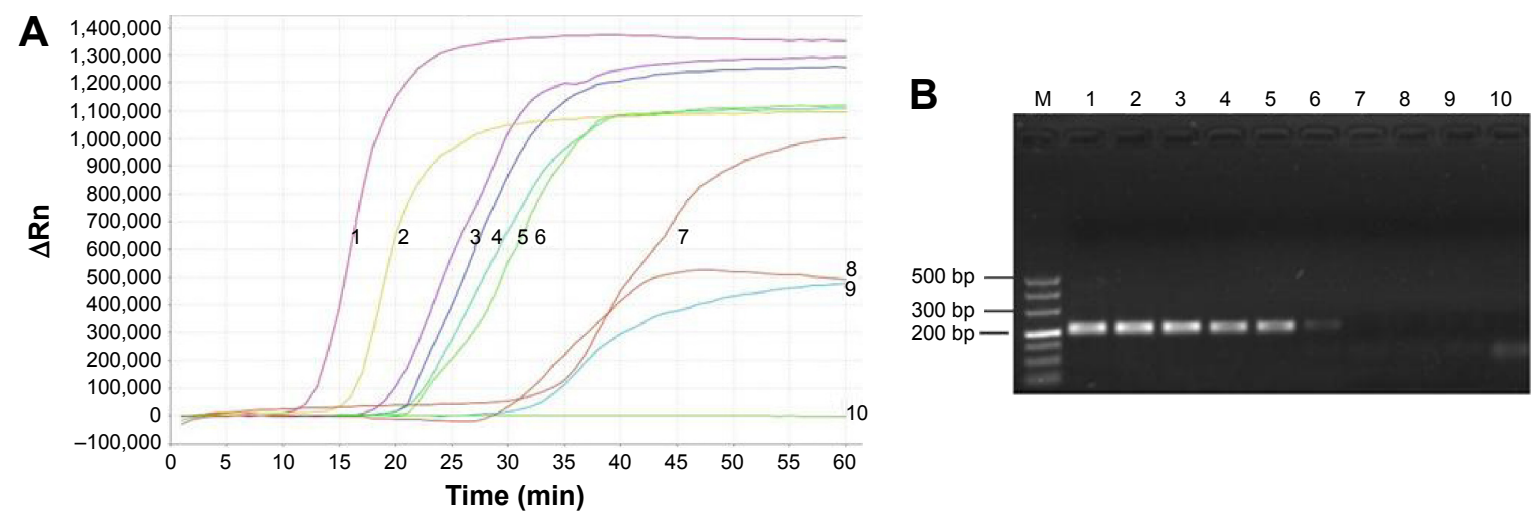

Figure I Sensitivity of LAMP method compared with PCR.

Notes: Detection limit of LAMP or PCR assays were performed using serial tenfold dilutions of the Pneumocystis plasmid. (A) LAMP method: line I, $\times 10^{9}$ copies $/ \mathrm{mL}^{\circ}$ line 2, $\times 10^{8}$ copies $/ \mathrm{mL}$; line 3, $\times 10^{7}$ copies $/ \mathrm{mL}$; line 4, $\times 10^{6}$ copies $/ \mathrm{mL}$; line 5, $\times 10^{5}$ copies $/ \mathrm{mL}$; line 6, $\times 10^{4}$ copies $/ \mathrm{mL}$; line 7, $\times 10^{3} \mathrm{copies} / \mathrm{mL}$; line $8, \times 10^{2}$ copies $/ \mathrm{mL}$; line 9, 50 copies $/ \mathrm{mL}$; line 10, 10 copies $/ \mathrm{mL}$. (B) PCR method: lane M, 100 bp DNA marker; lane I, $\times 10^{9}$ copies $/ \mathrm{mL}$; lane 2, $\times 10^{8} \mathrm{copies} / \mathrm{mL}$; lane 3, $\times 10^{7} \mathrm{copies} / \mathrm{mL}$; lane 4, $\times 10^{6}$ copies $/ \mathrm{mL}$; lane 5, $\times 10^{5}$ copies $/ \mathrm{mL}$; lane 6, $\times 10^{4}$ copies $/ \mathrm{mL}$; lane 7, $\times 10^{3}$ copies $/ \mathrm{mL}$; lane 8, $\times 10^{2}$ copies $/ \mathrm{mL}$; lane $9,50 \mathrm{copies} / \mathrm{mL}$; lane $10,10 \mathrm{copies} / \mathrm{mL}$. Abbreviations: LAMP, loop-mediated isothermal amplification; PCR, polymerase chain reaction. 
A

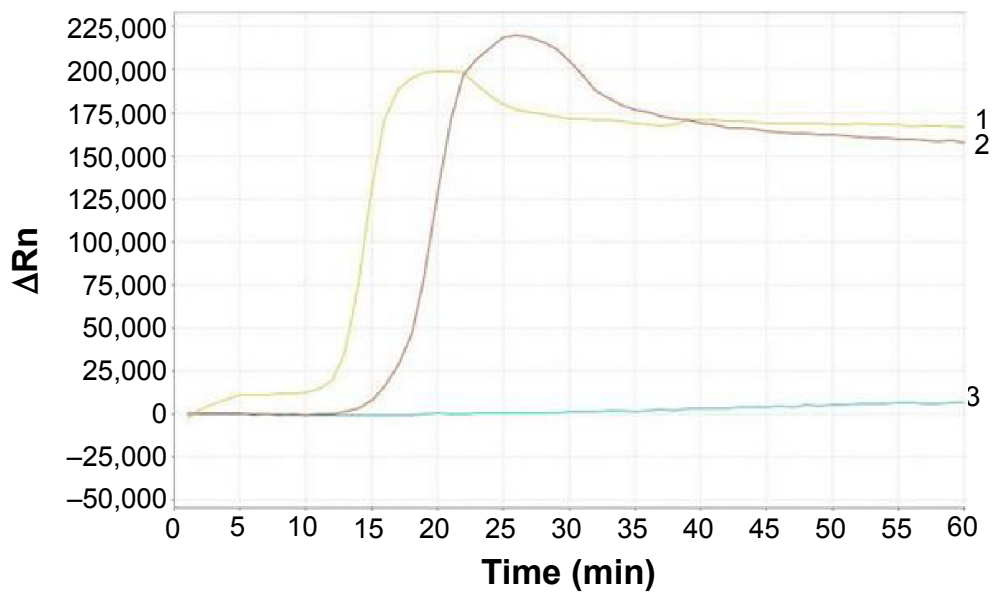

B 1

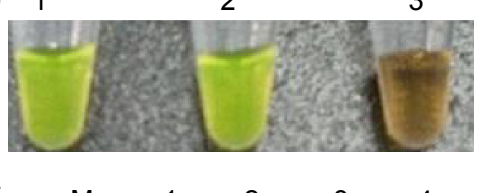

C

Figure 2 Examination of the products of LAMP for detecting the Pneumocystis jirovecii gene.

Notes: The products of LAMP were examined by three methods. (A) By real-time turbidity; (B) by either the naked eye or ultraviolet light after adding SYBR Green I; (C) by gel electrophoresis. (A and B) I, lung of PCP positive rat; 2, sputum specimen of patient; 3, lung of PCP negative rat. (C) Lane M, 2,000 bp DNA marker; lane I, lung of PCP positive rat; lane 2 and lane 3, sputum specimen of patients; lane 4, lung of PCP negative rat.

Abbreviations: LAMP, loop-mediated isothermal amplification; PCP, Pneumocystis pneumonia.

a specific target gene. It is a highly efficient, selective, and rapid DNA amplification technique for genetic screening of pathogens and had developed for the diagnosis of PCP. ${ }^{10-12}$ In this study, we developed a LAMP method, compared with the conventional PCR method, and detected the $P$. jirovecii specific gene from sputum specimens of patients with chronic pulmonary diseases. The results showed that there was no cross-reaction with other fungi or several bacteria in detecting the specific gene of $P$. jirovecii by the LAMP method, and the minimum detection limits by the LAMP was 50 copies $/ \mathrm{mL}$, whereas the conventional PCR could amplify $10^{4}$ copies $/ \mathrm{mL}$, it is at least 200 times more sensitive than PCR detection for sputum specimens. The reason for the difference between the two methods was that the LAMP uses three pairs of primers, which can be

Table 3 Microbes co-infection in 62 Pneumocystis jirovecii positive patients

\begin{tabular}{llll}
\hline Microorganism & Positive & Total & Positive rate (\%) \\
\hline Porphyromonas gingivalis & 10 & 16 & 62.5 \\
Fusobacterium nucleatum & 15 & 22 & 68.2 \\
Actinobacillus actinomycetem & 2 & 3 & 66.7 \\
Tannerella forsythia & 5 & 9 & 55.6 \\
Treponema pallidum & 5 & 13 & 38.5 \\
Acinetobacter baumannii & 6 & 7 & 85.7 \\
Fungi & 8 & 10 & 80.0 \\
Other bacteria & 11 & 18 & 66.8 \\
Total & 62 & 98 & 63.3 \\
\hline
\end{tabular}

Note: There were no statistically significant in difference microbe co-infection with Pneumocystis colonization $(P>0.05)$. amplified by the loop primers, which can greatly improve the detection efficiency. The LAMP method developed by Japanese scholars was used for the diagnosis of PCP; ${ }^{11,12}$ we first applied LAMP for detection the $P$. jirovecii colonization in patients with chronic pulmonary diseases. The results prove that the LAMP method is an applicable technology for evaluating the colonization of $P$. jirovecii from sputum specimens. The method is rapid, simple, cost effective, and less time-consuming.

The $P$. jirovecii is an atypical opportunistic fungus that causes pneumonia in immunosuppressed and immunocompetent individuals. The presence of $P$. jirovecii DNA in respiratory specimens without clinical signs and symptoms of pneumonia has been defined as "colonization" or "carriage", "subclinical infection" or "latent infection" $P$. jirovecii colonization in HIV-negative patients with various lung diseases has been reported., ${ }^{216-19}$ The positive rate of $P$. jirovecii DNA is $33.7 \%{ }^{16}$ and $70 \%{ }^{17}$ in bronchoalveolar lavage specimens in Turkey; $17.3 \%$ in COPD patients in North Lebanon ${ }^{18}$ and $7.3 \%$ in Iranian patients with various lung diseases, ${ }^{2}$ and $7.9 \%$ in COPD patients ${ }^{19}$ from pulmonary specimens. All of them used the nested PCR for detected gene of $P$. jirovecii. Here, we detected the colonization of $P$. jirovecii by LAMP and PCR method in sputa of HIV (-) patients with chronic pulmonary diseases. The results show that the positive rate of $P$. jirovecii DNA was up to $63.3 \%$ by LAMP method in sputa specimens of the patients with chronic pulmonary diseases in the People's Republic of China. It is much higher 
Table 4 Microbe infection in the patients with difference pulmonary diseases subpopulation

\begin{tabular}{|c|c|c|c|c|c|c|c|c|c|}
\hline \multirow[t]{2}{*}{ Disease } & \multicolumn{9}{|c|}{ Infective microbes } \\
\hline & P.g & F.n & A.a & T.f & T.p & A.b & Fungi & Other bacteria & Tota \\
\hline COPD & 4 & 7 & - & 2 & 2 & 4 & 6 & 6 & 31 \\
\hline ILDs & 3 & 5 & - & - & I & 2 & I & 4 & 16 \\
\hline $\mathrm{CF}$ & 2 & 3 & I & 2 & I & - & I & I & II \\
\hline $\mathrm{CB}$ & I & - & I & I & I & - & - & - & 4 \\
\hline Total & 10 & 15 & 2 & 5 & 5 & 6 & 8 & II & 62 \\
\hline
\end{tabular}

Note: There were no statistically significant between infective microbes in difference pulmonary diseases subpopulation $(P>0.05)$.

Abbreviations: A.a, Actinobacillus actinomycetem; A.b, Acinetobacter baumannii; CB, chronic bronchiectasis; CF, cystic fibrosis; F.n, Fusobacterium nucleatum; ILDs, interstitial lung diseases; P.g, Porphyromonas gingivalis; T.f, Tannerella forsythia; T.p, Treponema pallidum.

than previous reports. The reason may be related to higher sensibility of LAMP (the minimum detection limits by the LAMP was 50 copies $/ \mathrm{mL}$ ) than nested PCR. The role of the higher yield of $P$. jirovecii colonization in the respiratory diseases remains to be determined. The carriers of $P$. jirovecii are at a higher risk of $P$. jirovecii pneumonia, or they may transmit the fungus to other susceptible patients. ${ }^{7.8}$ Preventive measures should be given more concern.

In the last few years, there is growing evidence that the lung microbe has a significant impact on clinical outcome of chronic respiratory diseases. ${ }^{20-22}$ The relationship of the lung microbes with the $P$. jirovecii colonization and the role in the lung disease had drawn attention. ${ }^{23,24}$ We tested the microbes in sputum and investigated whether the $P$. jirovecii colonization may inhibit or promote by other microorganism in lung. The results show that more than ten microbes were discovered in the sputum in 62 patients, but did not show any statistical difference between $P$. jirovecii colonization with co-infection and those without co-infection, and even co-infection with different bacterial species. However, we detected the microbes in the sputum specimens, which could not really show the true picture of microbial population in the lung, and it is with the risk of contamination of oral microbes, despite the preventive measures taken to avoid oral microbial contamination. It will be more reliable to test the lung microbes in bronchoalveolar lavage fluid specimens.

A series of animal and human studies suggest that the Pneumocystis infection is strongly correlated with $\mathrm{CD} 4^{+}$ T-cell responses. ${ }^{25}$ Pneumocystis colonization occurred

Table 5 Pneumocystis colonization in patients with different CD4 ${ }^{+}$ T-cells

\begin{tabular}{llll}
\hline CD4 $^{+}$T-cells $/ \mathbf{m m}^{3}$ & Positive & Total & Positive rate (\%) \\
\hline$<410$ & 20 & 25 & $80.0^{*}$ \\
$>410$ & 42 & 73 & 57.5 \\
\hline
\end{tabular}

Note: ${ }^{*}$ Compared with the patients with $\mathrm{CD}^{+} \mathrm{T}$ lymphocyte counts $>410 / \mathrm{mm}^{3}$, $P<0.05$. when the CD4(+) T-cell count decreased to $<500$ cells $/ \mathrm{mL} .{ }^{26}$ In this study, $80.0 \%$ of Pneumocystis gene was tested positive in the group of $\mathrm{CD}^{+} \mathrm{T}$-cells counts $<410 / \mathrm{mm}^{3}$, which was significantly higher than $57.5 \%$ in the $\mathrm{CD}^{+} \mathrm{T}$-cells counts $>410 / \mathrm{mm}^{3}$ group $(P<0.05$, Table 5). These results support the findings of the importance of $\mathrm{CD}^{+} \mathrm{T}$-cells in defense against Pneumocystis, the high prevalence of Pneumocystis colonization even in immunocompetent patients with high $\mathrm{CD} 4^{+} \mathrm{T}$-cells counts.

The results of this study showed that prevalence of $P$. jirovecii colonization is particularly high in patients with chronic pulmonary diseases in the People's Republic of China, suggesting that those patient population is a major reservoir and source of $P$. jirovecii infection and that identification of such individuals may contribute to PCP prevention strategies. The results of detection indicate that LAMP was a good method for evaluation of the colonization of $P$. jirovecii in sputum specimen.

\section{Acknowledgments}

This work was supported by the National Natural Science Foundation of China (NSFC: 81370189, 81302271). The authors wish to acknowledge the staff members of the Division of Pulmonary, Department of Internal Medicine, Shengjing Hospital, and the First Affiliated Hospital, China Medical University, for their contribution to this study. The authors thank the staff members of Department of Microbiology and Parasitology for their helpful assistance.

\section{Author contributions}

Dong-Dong Wang developed the study design and carried out acquisition and interpretation of data, statistical analysis, manuscript preparation, and critical revision of intellectual contents. Dr Ming-Quan Zheng reviewed and edited the manuscripts. Nan Zhang and Chun-Li An contributed to screening patients, collecting sputum specimen, gene detection, acquisition and interpretation of data, revision of the 
article for important intellectual contents, and final approval of the version to be published. All authors contributed toward data analysis, drafting and revising the paper and agree to be accountable for all aspects of the work.

\section{Disclosure}

The authors report no conflicts of interest in this work.

\section{References}

1. Riebold D, Enoh DO, Kinge TN, et al. Pneumocystis jirovecii colonisation in HIV-positive and HIV-negative subjects in Cameroon. Trop Med Int Health. 2014;19(6):643-655.

2. Khodadadi H, Mirhendi H, Mohebali M, Kordbacheh P, Zarrinfar H, Makimura K. Pneumocystis jirovecii colonization in non-HIV-infected patients based on nested-PCR detection in bronchoalveolar lavage samples. Iran J Public Health. 2013;42(3):298-305.

3. Izadi M, Jonaidi Jafari N, Sadraei J, et al. The prevalence of Pneumocystis jirovecii in bronchoalveolar lavage specimens of lung transplant recipients examined by the nested PCR. Jundishapur J Microbiol. 2014; 7(12):e13518.

4. Morris A, Norris KA. Colonization by Pneumocystis jirovecii and its role in disease. Clin Microbiol Rev. 2012;25(2):297-317.

5. Hernández-Hernández F, Fréalle E, Caneiro P, et al. Prospective multicenter study of Pneumocystis jirovecii colonization among cystic fibrosis patients in France. J Clin Microbiol. 2012;50(12):4107-4110.

6. Pederiva MA, Wissmann G, Friaza V, et al. High prevalence of Pneumocystis jirovecii colonization in Brazilian cystic fibrosis patients. Med Mycol. 2012;50(5):556-560.

7. Gits-Muselli M, Peraldi MN, de Castro N, et al. New short tandem repeat-based molecular typing method for Pneumocystis jirovecii reveals intrahospital transmission between patients from different wards. PLoS One. 2015;10:e0125763.

8. Le Gal S, Pougnet L, Damiani C, et al. Pneumocystis jirovecii in the air surrounding patients with Pneumocystis pulmonary colonization. Diagn Microbiol Infect Dis. 2015;82:137-142.

9. Wang XL, Wei W, An CL. Retrospective study of Pneumocystis pneumonia over half a century in mainland China. J Med Microbiol. 2011;60(Pt 5):631-638.

10. Dhama K, Karthik K, Chakraborty S, et al. Loop-mediated isothermal amplification of DNA (LAMP): a new diagnostic tool lights the world of diagnosis of animal and human pathogens: a review. PakJ Biol Sci. 2014; 17(2):151-166.

11. Uemura N, Makimura K, Onozaki M, et al. Development of a loopmediated isothermal amplification method for diagnosing Pneumocystis pneumonia. J Med Microbiol. 2008;57(Pt 1):50-57.

12. Nakashima K, Aoshima M, Ohkuni Y, Hoshino E, Hashimoto K, Otsuka Y. Loop-mediated isothermal amplification method for diagnosing Pneumocystis pneumonia in HIV-uninfected immunocompromised patients with pulmonary infiltrates. $J$ Infect Chemother. 2014;20(12):757-761.
13. An CL, Gigliotti F, Harmsen AG. Exposure of immunocompetent adult mice to Pneumocystis carinii f. sp. muris by cohousing: growth of $P$. carinii f. sp. muris and host immune response. Infect Immu. 2003;71(4): 2065-2070.

14. An CL, Li S, Jiang L, Masanobu T. Detection of the Pneumocystis carinii by PCR and organism staining method. J China Med Univ. 1999;28(1):27-28 (in Chinese).

15. Wakefield AE, Cuiver L, Miller RF, Hopkin JM. DNA amplification on induced sputum samples for diagnosis of Pneumocystis carinii pneumonia. Lancet. 1991;337:1378-1379.

16. Özkoç S, Bayram Delibaş S, Erbaycu AE, Ergüden C, Akısü Ç. Investigation of Pneumocystis jirovecii colonization in patients with pulmonary diseases. Turkiye Parazitol Derg. 2014;38(4):214-219.

17. Özkoç S, Bayram Delibaş S. Investigation of Pneumocystis jirovecii pneumonia and colonization in iatrogenically immunosuppressed and immunocompetent patients. Mikrobiyol Bul. 2015;49(2):221-230.

18. Khalife S, Aliouat EM, Aliouat-Denis CM, et al. First data on Pneumocystis jirovecii colonization in patients with respiratory diseases in North Lebanon. New Microbes New Infect. 2015;6:11-14.

19. Sheikholeslami MF, Sadraei J, Farnia P, et al. Colonization of Pneumocystis jirovecii in chronic obstructive pulmonary disease (COPD) patients and the rate of Pneumocystis pneumonia in Iranian non-HIV(+) immunocompromised patients. Iran J Microbiol. 2013;5(4):411-417.

20. Nguyen LD, Viscogliosi E, Delhaes L. The lung mycobiome: an emerging field of the human respiratory microbiome. Front Microbiol. 2015;6:89.

21. Sethi S. Chronic obstructive pulmonary disease and infection. Disruption of the microbiome? Ann Am Thorac Soc. 2014;11(Suppl 1): S43-S47.

22. Sze MA, Hogg JC, Sin DD. Bacterial microbiome of lungs in COPD. Int J Chron Obstruct Pulmon Dis. 2014;9:229-238.

23. Sivam S, Sciurba FC, Lucht LA, et al. Distribution of Pneumocystis jirovecii in lungs from colonized COPD patients. Diagn Microbiol Infect Dis. 2011;71(1):24-28.

24. Kling HM, Shipley TW, Patil SP, et al. Relationship of Pneumocystis jirovecii humoral immunity to prevention of colonization and chronic obstructive pulmonary disease in a primate model of HIV infection. Infect Immun. 2010;78(10):4320-4330.

25. Fitzpatrick ME, Tedrow JR, Hillenbrand ME, et al. Pneumocystis jirovecii colonization is associated with enhanced Th1 inflammatory gene expression in lungs of humans with chronic obstructive pulmonary disease. Microbiol Immunol. 2014;58(3):202-211.

26. Kling HM, Shipley TW, Patil S, Morris A, Norris KA. Pneumocystis colonization in immunocompetent and simian immunodeficiency virusinfected cynomolgus macaques. J Infect Dis. 2009;199(1):89-96.
International Journal of COPD

\section{Publish your work in this journal}

The International Journal of COPD is an international, peer-reviewed journal of therapeutics and pharmacology focusing on concise rapid reporting of clinical studies and reviews in COPD. Special focus is given to the pathophysiological processes underlying the disease, intervention programs, patient focused education, and self management protocols.

\section{Dovepress}

This journal is indexed on PubMed Central, MedLine and CAS. The manuscript management system is completely online and includes a very quick and fair peer-review system, which is all easy to use. Visit $\mathrm{http}: / / \mathrm{www}$. dovepress.com/testimonials.php to read real quotes from published authors. 